\title{
Biology and fisheries of the spotted flounder (Citharus linguatula) caught by multiple gears with partial spatiotemporal overlaps
}

\author{
Marianna Pappa ${ }^{1}$, Anastasiia Chychykalo ${ }^{1}$, Martha Koutsidi ${ }^{1}$, Ninon Mavraki ${ }^{1, a}$, Evgenia Lefkaditou ${ }^{2}$, \\ Constantin Koutsikopoulos ${ }^{1}$ and Evangelos Tzanatos ${ }^{1, *}$ \\ ${ }^{1}$ Section of Animal Biology, Department of Biology, University of Patras, 26504 Rio, Patras, Greece \\ 2 Institute of Marine Biological Resources and Inland Waters, Hellenic Centre for Marine Research, Agios Kosmas, Elliniko, \\ 16610 Athens, Greece
}

Received 10 April 2017 / Accepted 8 August 2017

Handling Editor: Verena Trenkel

\begin{abstract}
Obtaining data to study fish biology can be a challenge if a stock is fished by a variety of gears with different effort units and different selectivity, particularly if these gears only partially overlap in space and time. In this work, we attempted to study the biology of the spotted flounder Citharus linguatula in the Patraikos Gulf and the adjacent central Ionian Sea (eastern Mediterranean) and to evaluate the current fisheries management. We characterized age composition and growth, length-at-maturity, and catch-perunit-effort (CPUE) of spotted flounder from the catches of bottom trawls, gillnets and trammel nets for the period autumn 2013-2014. Variation of fish total length, gonadosomatic index, hepatosomatic index and condition factor was analyzed using generalized additive models (GAMs) with regard to sex, date, fishing gear and depth. We also modeled CPUE fluctuations of each gear by date, depth, longitude and latitude using GAMs. Fish age ranged from 1 to 5 years. A slightly allometric growth was documented with females attaining larger sizes than males. Length-at-maturity was $163 \mathrm{~mm}$ for females and $169 \mathrm{~mm}$ for males. The seasonal change of gonad maturity stages and the gonadosomatic index indicated spawning in late summerautumn. Changes in length frequencies indicated that recruitment to the fisheries occurred in late springearly winter in shallow depth $(<40 \mathrm{~m})$. The catch composition of trawls and the CPUE model results suggested that the selectivity of this gear should be regulated to reduce catching immature individuals of spotted flounder. The results further indicated that the seasonal trawl closure of the Patraikos Gulf contributes to reduce catching juveniles.
\end{abstract}

Keywords: Citharidae / Flatfish / Multi-gear fisheries / Fisheries management / Dynamics / Growth

\section{Introduction}

Fisheries and oceanographic conditions have a direct impact on fish population behavior and biology (Garcia and Cochrane, 2005). Fisheries management is contingent on baseline information on basic biological traits (age composition, growth, and spatiotemporal distribution), as well as information on the spatiotemporal occurrence of spawning, settlement, recruitment and migration (e.g. Haynes et al., 2014). The successful completion of these stages is important

\footnotetext{
${ }^{a}$ Present address: Royal Belgian Institute of Natural Sciences, Operational Directorate Natural Environment, Marine Ecology and Management, Gulledelle 100, 1200 Brussels and 3de en 23ste Linieregimentsplein, 8400 Oostende, Belgium.

*Corresponding author: tzanatos@upatras.gr
}

for the persistence of the population. Understanding species biology can help design management measures and formulate advice on fishing gear characteristics and temporal or spatial closures (Caddy, 1997).

The spotted flounder Citharus linguatula (Linnaeus, 1758) is a sinistrally oriented benthic fish that belongs to the order Pleuronectiformes. Geographically, the species range spans the Mediterranean Sea and along the west coast of Europe and Africa, from Portugal to Angola (Nielsen, 1986). Its depth distribution ranges from 10 to $350 \mathrm{~m}$, with higher abundances occurring between 10 and $100 \mathrm{~m}$ (Sartor et al., 2002). It shows a preference for muddy and sandy seabed (Carpentieri et al., 2010). The species spawns in autumn and exhibits cryptic behavior, which form a unique trait profile not shared with other species in the area (Koutsidi et al., 2016).

In the eastern Mediterranean, the spotted flounder does not constitute a target species. In Greece it is often marketed but 
also discarded in both small-scale fisheries targeting hake (Merluccius merluccius) using gillnets (Tzanatos et al., 2007) and trawl fisheries targeting red mullet (Mullus barbatus) and hake (Machias et al., 2001). In Turkey, it is discarded by trawls (Gurbet et al., 2013). Despite the fact that the spotted flounder is not of great commercial interest, it is important to study this species to monitor fishing mortality and the effect of management (Gordo et al., 2016). The need for evaluating the effects of multi-gear fisheries on bycatch species is increasingly recognized (Dimitriadis et al., 2016) because differences in gear selectivity related to size, age and sex could have important implications for fisheries management (Lee et al., 2014).

Traditionally, the study of fish biology has included the collection of samples by fishing, preferably by trawling as its low selectivity guarantees a rather unbiased collection of individuals; these samples yield data on parameters like maturity and age structure (Gordo et al., 2016). However, there are obstacles to sampling from highly heterogeneous fisheries to acquire the information needed on the appropriate spatial and temporal scales: (a) Although scientific fishing surveys (e.g. Mediterranean International Trawl Survey - MEDITS) provide samples in a standardized manner, as they are usually carried out in a specific time frame within the annual cycle (for MEDITS the beginning of summer) they cannot be used on their own to study seasonal dynamics but need to be combined with year round samples from commercial fisheries (e.g. Carbonara et al., 2015). (b) Even though, as stated above, sampling from trawls is generally preferable, in some cases, e. g. when a significant proportion of the distribution of a stock is outside the trawl fishing grounds due to legal restrictions or seabed substrate type, they are unsuitable. In these cases, other more selective gears such as nets and longlines have been used (e.g. Matić-Skoko et al., 2012). (c) Seasonal trawl restrictions may not allow the collection of samples throughout the year. (d) In areas like the eastern Mediterranean, there are legislated spatial closures for industrial fisheries in shallow depth (Tserpes et al., 2011) and also small-scale fishermen tend to avoid gear loss or conflicts with industrial fishermen by not fishing far from the coast. (e) As a result, fishing grounds of industrial (trawl, purse seine) and small-scale fisheries (e.g. gillnets, trammel nets and longlines) generally do not overlap. This spatial separation makes it difficult to sample a population from its entire distribution range (across different depths and habitat types) using one gear alone. Consequently, it is necessary to develop an approach that allows the integrated study of species biology in space and time.

The present study aims to examine the biology and ecology of the spotted flounder in the area of the Patraikos Gulf and the adjacent part of the central Ionian Sea. This includes the examination of length and age composition, fluctuations of biological indices in space and time and differences between different fishing gears. The study further aims to combine this information with catch data (fish abundance, length composition) from the different gears catching this species in order to provide recommendations for fisheries management. Catch per unit of effort fluctuations are analyzed with regard to spatiotemporal variables in order to evaluate the current management scheme and, if necessary, formulate further recommendations.
20.8

21.3

21.8

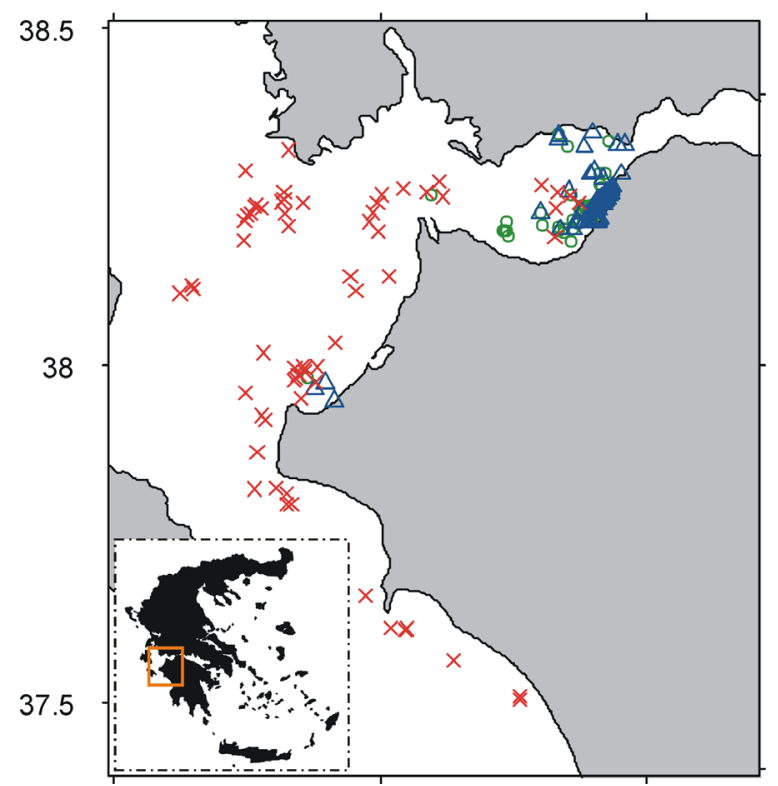

Fig. 1. Map of the study area and location of the 236 fishing operations sampled onboard commercial fishing vessels (catch samples). The detailed biological samples (collection of spotted flounder individuals) were collected in a subset of 33 fishing operations. Red crosses indicate trawl fishing operations, green circles indicate gillnets and blue triangles indicate trammel nets. In the inlet, the study area within the map of Greece is shown.

\section{Materials and methods}

The study was carried out in the Patraikos Gulf(Ionian Sea, eastern Mediterranean) and the adjacent part of the central eastern Ionian Sea (Fig. 1). Data collection included (a) the collection of catch data for the investigation of spotted flounder presence and abundance (catch samples) in trawl and net (gillnet and trammel net) catches and (b) the collection of individuals for the determination of biological, age and growth parameters (detailed biological samples). In the study area, bottom trawling is (a) prohibited in depths shallower than $50 \mathrm{~m}$ or less than 1.5 nautical miles from the shore, (b) banned from the beginning of June to the end of September (throughout the 6 nautical miles territorial waters of Greece) and (c) allowed within the limits of the Patraikos Gulf only from the beginning of December to the end of February. Hence, trawl sampling from a relatively wider area was used in this study to sample catches. Contrary to bottom trawling, there are no spatial or temporal prohibitions for passive small-scale fishing gears including gillnets and trammel nets.

\subsection{Catch samples}

The spotted flounder catch samples were collected by scientists onboard commercial fishing vessels during the period October 2013 to December 2014 in application of the European Union Data Collection Framework (EC 199/2008) in the area of the eastern Ionian Sea (GFCM area: GSA20). From the data collected in the entire eastern Ionian, only those 
representing fishing operations (trawl hauls or net sets) in the wider study area (Patraikos Gulf and adjacent central Ionian Sea) were used. The data used comprised catch biomass and length composition of spotted flounder from 236 fishing operations: 71 trawl hauls, 63 gillnet sets, and 102 trammel net sets. The fishing operations were distributed partially in different depth zones (Fig. 1) with trammel nets operating in relatively shallow depths (minimum depth: $5 \mathrm{~m}$; maximum depth: $110 \mathrm{~m}$; average depth: $36 \mathrm{~m}$ ), gillnets in intermediate depths $(24 \mathrm{~m} ; 122 \mathrm{~m} ; 66 \mathrm{~m})$ and trawls fishing deeper $(50 \mathrm{~m}$; $546 \mathrm{~m} ; 85 \mathrm{~m})$. For each fishing operation the average depth, geographic coordinates and trawl haul duration or length of net sets were recorded.

\subsection{Detailed biological samples and laboratory analyses}

A total of 509 spotted flounder individuals (biological samples) were collected in the Patraikos Gulf and the adjacent part of the central Ionian Sea during 33 fishing trips. The fish were collected from the catch of three different fishing gears: trawls (182 individuals), gillnets (245 individuals) and trammel nets ( 81 individuals). Fish samples were frozen and transported to the laboratory for analysis. In the laboratory, fish total length (TL) was measured to the nearest mm and fish were weighted for total weight (TW), liver and gonad weight with a precision of $0.1 \mathrm{mg}$. Using these data, the gonadosomatic index $(\mathrm{GSI})=100 \times$ gonad weight/total weight, the hepatosomatic index $(\mathrm{HSI})=100 \times$ liver weight $/$ total weight, and the condition factor $(\mathrm{CF})=$ total weight $\times 10^{5} /$ (total length $)^{3}$ were calculated. Additionally, sex and stage of sexual maturity of individual fish were determined based on the MEDITS scale. The MEDITS scale is used for the macroscopic identification of sexual maturity stages. It consists of five maturity stages ( 0 : undetermined, 1 : immature, 2: developing, 3: mature, 4: spent) that can be defined by characteristics like gonad color, shape, robustness and size (in relation to the size of the body cavity) as well as the visibility and ease of release of eggs/sperm (for more details see Anonymous, 2013).

Ageing was carried out based on the interpretation of sagittal otolith macrostructure. We used the otoliths of the blind side, as in these the nucleus is more central compared to those of the ocular side making their macrostructure interpretation easier (Armsworthy and Campana, 2010; Cengiz et al., 2013, 2014). Otoliths were stored in glycerin. For the age determination they were placed in a petri dish filled with water with their distal frontal side upwards. The number of annual rings was determined under a stereoscope using transmitted light.

The length-weight relationship coefficients $a$ and $b$ were estimated for each sex separately and for all fish (including both sexes and immature individuals) by linear regression using the logarithm transformed form of the relationship: $\log (\mathrm{TW})=\log (a)+b \times \log (\mathrm{TL})$. Even though both the condition factor and the length-weight relationship incorporate the same variables (length and weight), they convey different information: the condition factor indicates changes in nutritional condition, while the length-weight relationship shows the growth pattern followed for a given species (Jin et al., 2015). Thus, both variables were estimated in the present study.
Length-at-maturity $\left(L_{50}\right)$ indicates the size at which $50 \%$ of the individuals are mature for reproduction. $\mathrm{TL}_{50}$ was determined by sex using the logistic function (Fryer, 1991):

$$
P=\frac{\mathrm{e}^{\left(v_{1}+v_{2} \cdot \mathrm{TL}\right)}}{1+\mathrm{e}^{\left(v_{1}+v_{2} \cdot \mathrm{TL}\right)}},
$$

where $v_{1}$ represents the intercept and $v_{2}$ the slope of the curve after applying a $\log$ transformation. The value of $\mathrm{TL}_{50}$ can then be estimated from the following expression:

$$
\mathrm{TL}_{50}=\frac{v_{1}}{v_{2}} \text {. }
$$

The parameters $v_{1}$ and $v_{2}$ were estimated by fitting a logistic function to the proportion of mature individuals per size class.

\subsection{Modeling}

Individual TL, GSI, HSI and CF of the biological data (detailed biological samples) were modeled using generalized additive models (GAMs). GAMs are non-parametric generalizations of the multiple linear regression with fewer limitations on the underlying data distribution (Hastie and Tibshirani, 1990). The explanatory variables used in each model were: (a) fishing date, used as a continuous variable (fishing day $=0$ on $31 / 10 / 2013$, the first date of sampling) and modeled using a cyclic regression spline, (b) depth, (c) the fishing gear type (trawl, gillnet and trammel net) and (d) sex (male, female, immature/undetermined). Geographic coordinates (longitude, latitude) were not used as explanatory variables as the majority of the fish individuals were sampled from a relatively small area (mainly Patraikos Gulf). Models were fitted to all sampled individuals (juveniles and adults) and also separately to juveniles and adults. Juvenile and adult individuals were distinguished by a threshold length of $166 \mathrm{~mm}$, based on the average length-at-maturity for the two sexes (see Sect. 3.1). This approach was preferred over using a categorical variable representing maturity, as habitat relationships can change dramatically with ontogeny for flatfish (Furey and Rooker, 2013).

Because the different gears have different and not directly comparable measures of fishing effort and patterns of selectivity, each gear was analyzed separately regarding catch data (catch samples). For trawls, catch-per-unit-effort (CPUE) was calculated as catch biomass $(\mathrm{kg})$ per hour of trawling and for gillnets and trammel nets as catch biomass $(\mathrm{kg})$ per $1000 \mathrm{~m}$ of net length. CPUE was log-transformed as $\log (\mathrm{CPUE}+1)$ and modeled again with GAMs using depth, date, longitude and latitude as explanatory variables. Even though it was possible to use non-transformed CPUE values, we preferred to use the log-transformation as it is the standard practice in fisheries studies (e.g. Winker et al., 2013; Keller et al., 2017). For trawl and trammel net gears, where a significant number of zero values were recorded, we applied the Delta-X-error method (Vignaux, 1996). This method separately models the probability of capture using presence-absence matrices (with presence indicating that the species was caught, while absence indicates that it was not caught), from the actual abundance in non-zero fishing operations (positive CPUE values). In 
gillnets, in the large majority of fishing operations, spotted flounders were recorded in the catch, so the log-transformed CPUE-values were used including zero values, without incorporating the Delta-X-error method.

All GAM analyses were carried out in $\mathrm{R}$ language (R Development Core Team, 2008), using the library mgcv (Wood, 2006). We used the Akaike information criterion (AIC, Chambers and Hastie, 1992) to examine all combinations of explanatory variables and to compare models. The selection of explanatory variables to include in each final GAM model was based on which variable combination from all possible combinations resulted in the lowest AIC value (Supplementary Tab. 1a for catch data: CPUE models, Supplementary Tab. 1b for detailed biological data: TL, GSI, HSI and CF-models). The AIC cannot be used to infer about statistical significance of explanatory variables for the response variable. It is rather a tradeoff between model goodness-of-fit and complexity. Thus, we evaluated the explanatory variables by the analysis of deviance of the model variables at a significance level of $\alpha=0.05$. The selection of distributions (catch data positive values: Gaussian, catch data presence-absence values: binomial, biological data: Gamma function) and link functions (catch data positive values: identity, catch data presenceabsence values: probit or logit, biological data: $\log$ ) was based on residual plots. Over-fitting was avoided by limiting the maximum number of degrees of freedom in the splines to four (similar e.g. to Zucchetta et al., 2010, however Sandman et al., 2008, propose using even fewer degrees of freedom), by setting the number of knots used in the smoother to five.

\section{Results}

\subsection{Spotted flounder biology}

The fish TL in the biological samples varied between 110 and $256 \mathrm{~mm}$, while in the catch samples the range was $42-306 \mathrm{~mm}$ (94.4\% of the fish sizes within the range of the biological samples collected). The length frequencies of the individuals in the catch samples measured onboard by gear are presented in Supplementary Figure 1a and b. In the detailed biological samples minimum and maximum lengths were observed in November and in summer respectively. However, small individuals were also caught in May $(<150 \mathrm{~mm}$ TL $)$ and large ones were recorded in February ( $>200 \mathrm{~mm}$ TL, Fig. 2). Similarly, in the onboard samples minimal-length individuals were recorded in autumn-early winter (both years), while small individuals were also caught in spring (Supplementary Fig. 1b). In the biological sample, individuals smaller than $150 \mathrm{~mm}$ in TL constituted $55 \%$ of the total in January and around $20 \%$ in November, December and May.

The estimated ages ranged between 1 and 5 years (see agelength key provided in Supplementary Tab. 2). Most individuals of both sexes belonged to the age group of 3year-old fish. The length-weight relationship coefficients indicated a slightly allometric growth for both sexes (Fig. 3).

All stages of sexual maturity were observed in the biological samples (Fig. 4). Mature specimens were found during the months July-November (not in September but this is probably due to the small sample size in that month); among females and males aged 1 year old or older. In that period, the majority of individuals observed were female $(61 \%)$. The smallest fish that had reached maturity were 133 and $127 \mathrm{~mm}$ for females and males respectively, while the $L_{50}$ was estimated at $163 \mathrm{~mm}$ for females and at $169 \mathrm{~mm}$ for males.

\subsection{Models for biological samples}

GAMs revealed a statistically significant variation in individual TL between different dates of capture, fishing gears and sexes (Tab. 1, Fig. 5a-c). Individual TL (average $m=170 \mathrm{~mm}$, standard deviation $(\mathrm{SD})=25 \mathrm{~mm}$ ) was highest in February (day $\sim 90-100$; Fig. 5a). The largest fish were observed in the catches of gillnets $(m=181 \mathrm{~mm}, \mathrm{SD}=19 \mathrm{~mm}$, Fig. 5b) and trammel nets $(m=179 \mathrm{~mm}, \mathrm{SD}=25 \mathrm{~mm})$ with significantly lower sizes caught by trawls $(m=153 \mathrm{~mm}$, $\mathrm{SD}=20 \mathrm{~mm})$. Females reached higher TL $(m=179 \mathrm{~mm}$, $\mathrm{SD}=23 \mathrm{~mm}$, Fig. $5 \mathrm{c})$ than males $(m=169 \mathrm{~mm}, \mathrm{SD}=25 \mathrm{~mm})$. Considering juveniles (Tab. 1, Supplementary Fig. 2a), the largest individuals were caught by gillnets $(m=155 \mathrm{~mm}$, $\mathrm{SD}=7 \mathrm{~mm}$ ), intermediate TL values were found for trammel nets $(m=151 \mathrm{~mm}, \mathrm{SD}=11 \mathrm{~mm})$ and the lowest values were recorded for trawls $(m=143 \mathrm{~mm}, \mathrm{SD}=13 \mathrm{~mm})$. Similarly, the TL of adult fish (Tab. 1, Supplementary Fig. 2b) was largest in gillnet catches $(m=191 \mathrm{~mm}, \mathrm{SD}=18 \mathrm{~mm})$, slightly smaller in trammel nets $(m=188 \mathrm{~mm}, \mathrm{SD}=15 \mathrm{~mm})$ and lowest in trawls $(m=179 \mathrm{~mm}, \mathrm{SD}=11 \mathrm{~mm})$. In mature fish, females had larger TL than males and fish of unidentified sex. In adult fish, the largest TL values were observed in winter (maximum monthly average in February $m=192 \mathrm{~mm}, \mathrm{SD}=18 \mathrm{~mm}$ ) and the lowest in autumn (in October $=181 \mathrm{~mm}, \mathrm{SD}=11 \mathrm{~mm}$ ).

The GSI $(m=0.74, \mathrm{SD}=0.78)$ also showed significant differences between capture day, fishing gear and sex (Tab. 1, Fig. 5d-f). GSI values were higher in late summer/autumn (peaking in August, Fig. $5 \mathrm{~d}, m=1.32, \mathrm{SD}=1.00$ ) and lower in winter and spring (minimum in January, $m=0.35, \mathrm{SD}=0.20$ ). However, the distribution of residuals indicated a different pattern in juvenile fish as there was an aggregation of negative residuals. The average GSI was higher in fish caught by gillnets (Fig. 5e, $m=0.98, \mathrm{SD}=0.93$ ), intermediate in trammel nets $(m=0.77, \mathrm{SD}=0.74)$, while the lowest values were observed in samples collected from trawl catches $(m=0.49$, $\mathrm{SD}=0.37)$. As expected, the GSI of immature individuals was much lower (Fig. 5 f, $m=0.17$, $\mathrm{SD}=0.22$ ) than that of mature females $(m=1.08, \mathrm{SD}=0.85)$ and males $(m=0.74, \mathrm{SD}=0.73)$. Examining adult fish only yielded similar patterns to all fish, indicating high GSI in autumn and low in fish caught by trawls and those of unidentified sex (Tab. 1, Supplementary Fig. 2b). In juvenile fish, the GSI was highest in fish caught with trammel nets $(m=0.71, \mathrm{SD}=0.96)$ and lowest in the trawl catches $(m=0.38, \mathrm{SD}=0.35$, Supplementary Fig. 2a). In this group, females had the highest GSI $(m=0.79, \mathrm{SD}=0.75)$, males had intermediate GSI $(m=0.41, \mathrm{SD}=0.43)$ and fish of unidentified sex the lowest $(m=0.15, \mathrm{SD}=0.08)$.

According to the GAM results a significant variation in HSI $(m=1.08, \mathrm{SD}=0.79)$ was found between fishing gears, day and depth (Tab. 1, Fig. 5g-i). The highest HSI was found in summer (with a monthly average of 2.25 in August), however the residuals indicated some very low HSI-values (Fig. 5g). Individuals caught by gillnets had higher HSI values ( $m=1.45$, $\mathrm{SD}=0.82)$ compared to those caught by trawls $(m=0.62$, $\mathrm{SD}=0.49$ ), while HSI values of fish caught in trammel nets $(m=0.80, \mathrm{SD}=0.54)$ reached intermediate values (Fig. $5 \mathrm{~h})$. 

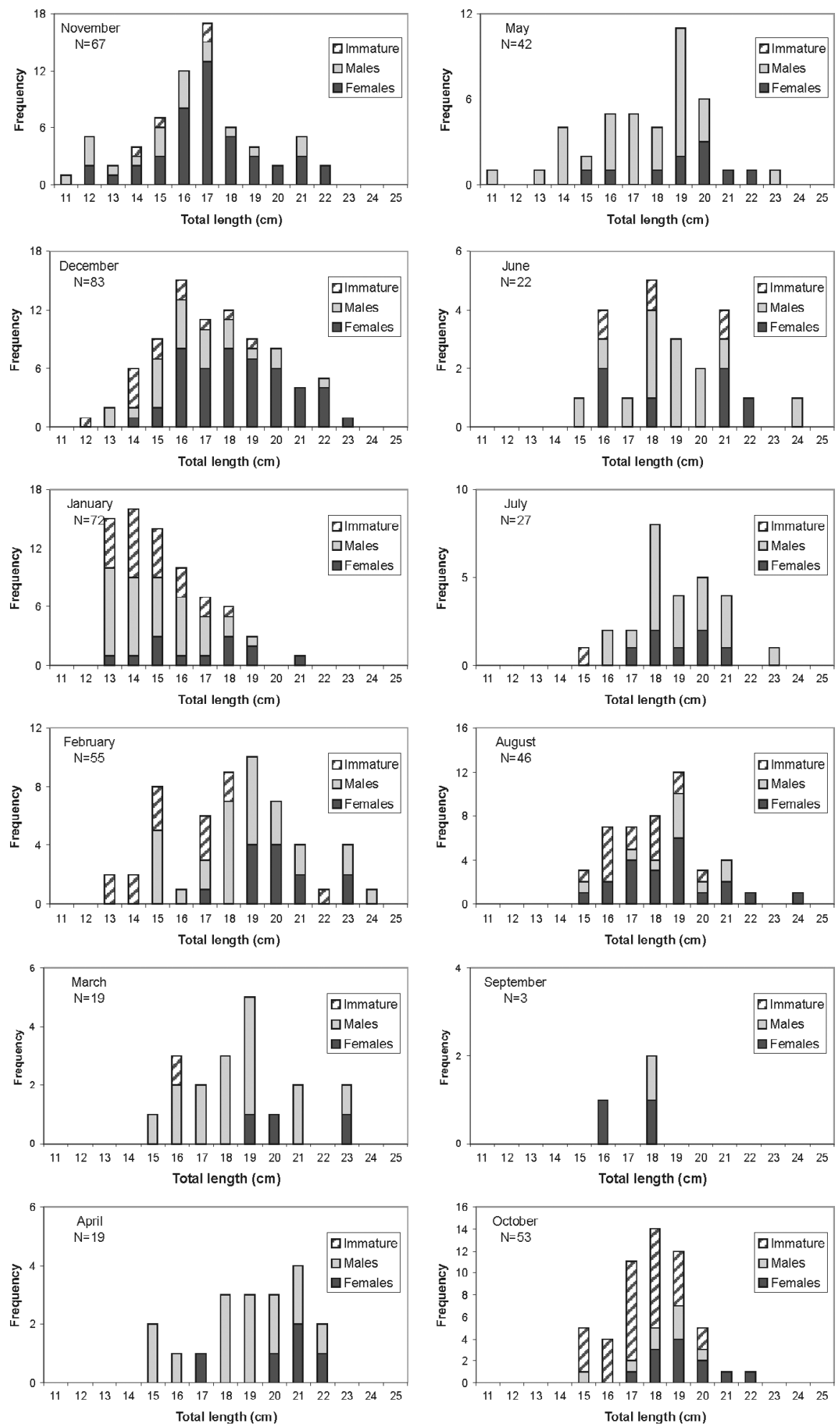

Fig. 2. Length frequency of spotted flounder in the Ionian Sea recorded monthly by sex during the period November 2013-October 2014 in the detailed biological samples from trawls, gillnets and trammel nets.

The HSI decreased with depth down to $50 \mathrm{~m}$, then increased slightly until $80 \mathrm{~m}$ and then decreased again (Fig. 5i). A different HSI/depth pattern was found for juveniles, with higher HSI below $80 \mathrm{~m}$ (Supplementary Fig. 2a). Similar HSI fluctuations with date were found for juveniles, adults and all individuals combined. For adult fish gillnets caught the fish with the highest HSI and trawls the ones with the lowest.

Finally, $\mathrm{CF}(m=0.73, \mathrm{SD}=0.06)$ was found to fluctuate depending on date and sex (Fig. 5j, k) though the best model only explained $12 \%$ of deviance for all individuals and $20 \%$ for 
mature ones (Tab. 1). The highest $\mathrm{CF}$ values were observed in summer (Fig. 5j, maximum $=0.93$ ) and the lowest in autumnearly winter (minimum $=0.56$ ). Females had slightly higher CF (Fig. 5k, $m=0.74, \mathrm{SD}=0.07$ ) than fish of unknown sex (mainly immature, $m=0.71, \mathrm{SD}=0.05$ ), while males had intermediate values. While the effect of gear on CF for all fish combined was not significant, contrasting patterns were found for juveniles and adult individuals. Juveniles caught by trawls had higher $\mathrm{CF}$ and those caught by gillnets showed lower values, contrary to adults (Supplementary Fig. 2a, b). Similar patterns of $\mathrm{CF}$ variation with date as for all individuals were documented for juveniles and adults separately. In adult fish, females had higher CF than males and fish of unidentified sex.

\subsection{Models for catch samples}

In general, spotted flounder CPUEs per set were higher for gillnets $(m=163 \mathrm{~g} / 1000 \mathrm{~m}$ of net, $\mathrm{SD}=207 \mathrm{~g} / 1000 \mathrm{~m})$ than trammel nets $(m=53 \mathrm{~g} / 1000 \mathrm{~m}, \mathrm{SD}=121 \mathrm{~g} / 1000 \mathrm{~m})$. Trawls caught on average $341 \mathrm{~g} / \mathrm{h}$ per haul $(\mathrm{SD}=496 \mathrm{~g} / \mathrm{h})$.

The probability of catching spotted flounder was $70 \%$ for trawls and highest in the period from October to December 2014 (82\% on average for this period) and in the eastern waters of the Patraikos Gulf (Tab. 2, Fig. 6b). The model for positive (non-zero) abundances did not reveal any significant variations for trawls hence no explanatory variables were selected $(m=484 \mathrm{~g} / \mathrm{h}, \mathrm{SD}=530 \mathrm{~g} / \mathrm{h})$.

Of the three gears examined, trammel nets were least likely to catch spotted flounder ( $28 \%$ probability). No significant differences were found for the presence/absence data of trammel nets. For non-zero abundance values from this gear, we found significant effects of depth and date (Tab. 2, Fig. 6c, d). The highest abundances were documented at 20-30 $\mathrm{m}$ depth and during summer.

Finally, only date had a significant effect on gillnet CPUE, with maximum values in July $(m=654 \mathrm{~g} / 1000 \mathrm{~m}$, $\mathrm{SD}=132 \mathrm{~g} / 1000 \mathrm{~m})$ and a local maximum in October $(m=514 \mathrm{~g} / 1000 \mathrm{~m}, \mathrm{SD}=447 \mathrm{~g} / 1000 \mathrm{~m})$.

Combining CPUE, length composition and length-atmaturity estimates (the latter two allowing an estimation of the relevant composition in juvenile and adult fish) revealed that gillnet and trammel net catches consisted mainly of adult fish, contrary to those of trawls (Fig. 7). Trawls caught mainly juvenile fish in the wider area of the central Ionian, whereas comparatively higher proportions of adult fish were caught when fishing in the inner Patraikos Gulf during the winter months.

\section{Discussion}

In the present work, we examined the multi-gear character of the spotted flounder fishery. In the Mediterranean, the few available studies on the multi-gear approach mostly focus on gear competition and are usually designed using an experimental setup (different fishing gears fishing at a number of sampling stations in different seasons, e.g. Stergiou and Erzini, 2002). Our approach followed the fishing activity of a commercial fleet and not an experimental scheme. It examined the spatial and temporal dimensions of fisheries as they were actually taking place and for this may
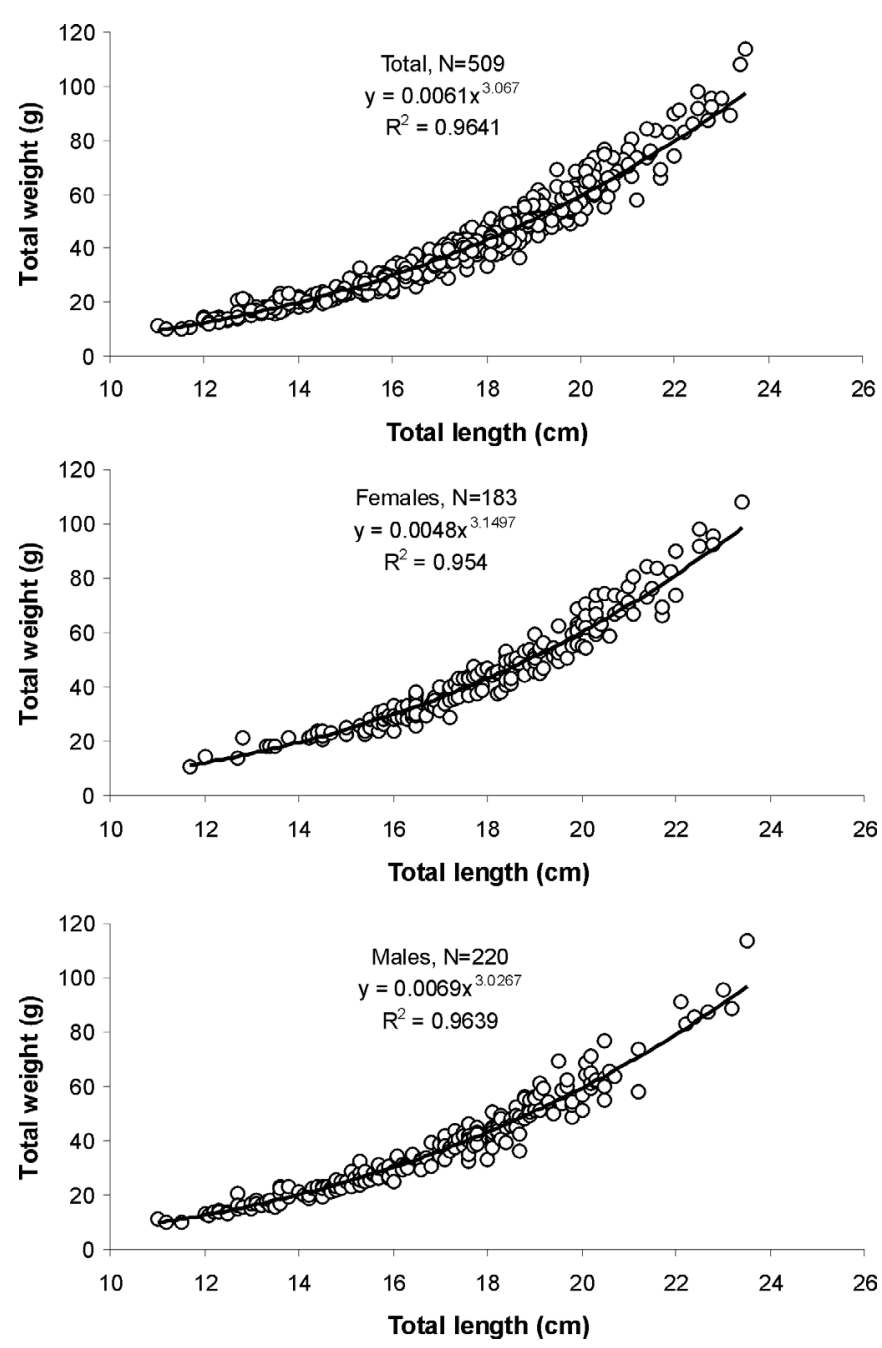

Fig. 3. Length-weight relationship $\mathrm{TW}=a \times \mathrm{TL}^{b}$ for total - including immatures (top), female (middle) and male (bottom) spotted flounder individuals. The factors $a$ and $b$ were estimated by linear regression of the log-transformed relationship. The adjusted $R^{2}$ and $p$ of the linear regression of the log-transformed values are given.

provide a more realistic evaluation of the effects of the different gears on the stock examined.

There was a higher percentage of adult fish in the catches of small-scale passive gears compared to bottom trawls. However, it seems that in the Patraikos Gulf adult fish constituted an important percentage of trawl catches, at least in the winter months when they are allowed to operate there. While almost the entire Patraikos Gulf is comparatively shallow $(<100 \mathrm{~m})$, in the Ionian Sea the continental shelf is very narrow and great depths are reached close to the shore in some locations. Consequently, only a small part of its area extends down to $100 \mathrm{~m}$. The difference in the area of seabed covering small depths between the Patraikos Gulf and the Ionian Sea can have profound effects on the success of recruitment. The nursery size hypothesis stipulates that flatfish recruitment is constrained by the extent of the nursery area (Van der Veer et al., 2000; but see Yamashita et al., 2000 who document high recruitment in a relatively small area provided the conditions are favorable). Factors apart from depth, like 


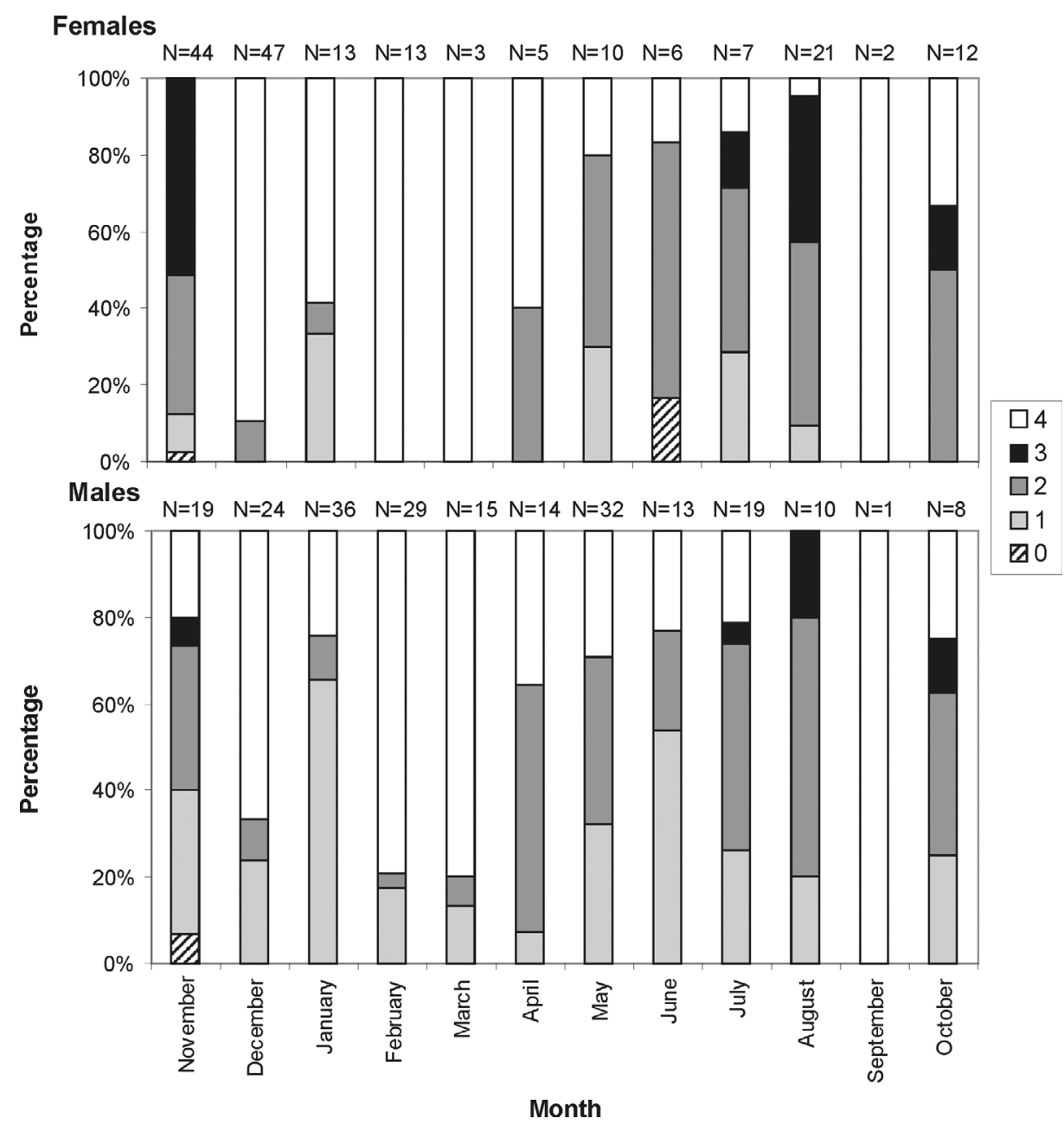

Fig. 4. Monthly $\%$ percentages of spotted flounder at each stage of maturity by sex. Maturity stages: 0 , undetermined; 1 , immature/virgin; 2 , developing/recovering/maturing; 3, mature/spawner; 4, spent/resting. Only fish potentially mature (with TL higher than minimum of mature individuals by sex) are included. Number of individuals where maturity stage was identified by month and sex are indicated.

sediment type and near-seabed temperature, can also have a significant effect on the extent of the nursery area (Gibson, 1994; Florin et al., 2009; Furey and Rooker, 2013; Wilson et al., 2016). Similarly, habitat quality seems to influence the body condition of two flatfish populations in the Bering Sea (Yeung and Yang, 2017). Temperature, salinity, depth and substrate have been shown to affect the preferred habitat of flatfish nurseries (see Cabral et al., 2007 and references therein).

Other studies in the Mediterranean and southern Europe have also demonstrated that different fleet segments may exploit different fractions of a stock (e.g. Martin et al., 1999; Erzini et al., 2003; Fabio et al., 2016). While size is the parameter most commonly examined, differences in other biological parameters have been documented for common cuttlefish caught by trawls, nets and traps in the northern Adriatic Sea (Bettoso et al., 2016). As management decisions regulating only one segment can have unforeseen effects (Lleonart et al., 2003), it is necessary to study fisheries resources taking into account the multi-gear element of these fisheries.

The findings of the present study provide the first information about the biology and the population structure of the spotted flounder in the Ionian Sea (an overview is provided in Fig. 8). Similar to other studies for this species in the Mediterranean (Vassilopoulou and Papaconstantinou, 1994; Garcia-Rodríguez and Esteban, 2000; Cengiz et al., 2014), female individuals were found to be larger than males. In the Atlantic, however, similar maximum sizes of males and females have been documented (Teixeira et al., 2010). Larger female sizes have also been reported for other flatfish species (e.g. Lozán, 1992; Landa and Piñeiro, 2000; Gerritsen et al., 2010; Cengiz et al., 2013). According to Vassilopoulou and Papaconstantinou (1994) this difference is due to the fact that males are smaller at first maturity.

In the study area, the spotted flounder starts breeding from the second year of its life during the period from July to November. In the western Mediterranean, the spawning period of the species has been recorded as June/July (Planas and Vives, 1956) and more recently from August to November (Garcia-Rodríguez and Esteban, 2000), while in the northeastern Aegean Sea it is from September to November (Cengiz et al., 2014). In the northeastern Atlantic, similar to this study, Teixeira et al. (2010) documented autumn spawning, and estimated maturity at 2 years at an $L_{50}$ of $190 \mathrm{~mm}$. Lower 
Table 1. Results of the generalized additive models (GAMs) on the effects of fishing gear, sex, day of fishing and depth (independent variables) on spotted flounder individual total length (TL), gonadosomatic index (GSI), hepatosomatic index (HSI), and condition factor (CF) for all individuals and separately for juveniles and mature/adult fish. The variables denoted by $\mathrm{s}()$ were considered continuous and a spline function was used for fitting. $F$-values of the analysis of deviance are indicated for each independent (explanatory) variable. Variables denoted by “-_" were not included according to the Akaike information criterion selection. Significant effects at the 0.05 confidence level are denoted by an asterisk and in bold typeface. The percentage of deviance explained by the final model (including only the variables with significant effects) is also indicated.

\begin{tabular}{|c|c|c|c|c|c|c|}
\hline \multirow[t]{2}{*}{ Sample } & \multirow{2}{*}{$\begin{array}{l}\text { Dependent } \\
\text { variable }\end{array}$} & \multicolumn{4}{|c|}{ Independent variables } & \multirow{2}{*}{$\begin{array}{l}\text { Deviance } \\
\text { explained }(\%)\end{array}$} \\
\hline & & s(date) & s(depth) & gear & $\operatorname{sex}$ & \\
\hline \multirow{2}{*}{$\begin{array}{l}\text { All fish } \\
N=509\end{array}$} & GSI & $23.60 *$ & - & $21.22 *$ & $163.07 *$ & 49.6 \\
\hline & HSI & $16.45^{*}$ & $3.33^{*}$ & 21.54* & - & 36.9 \\
\hline \multirow{4}{*}{$\begin{array}{l}\text { Juveniles } \\
N=212\end{array}$} & $\mathrm{TL}$ & - & 0.80 & - & $19.36^{*}$ & 18.0 \\
\hline & GSI & 0.01 & - & $4.61 *$ & $41.30 *$ & 33.4 \\
\hline & HSI & $5.33^{*}$ & $3.64 *$ & - & 2.40 & 30.3 \\
\hline & $\mathrm{CF}$ & $7.48^{*}$ & - & $5.57^{*}$ & - & 12.7 \\
\hline
\end{tabular}

values of $L_{50}$ have been estimated in the northeastern Aegean Sea (150 $\mathrm{mm}$ for females and $140 \mathrm{~mm}$ for males - Cengiz et al., 2014). The differences between these studies could be attributed to differences in environmental parameters like temperature and productivity (Wootton, 1998).

In the present study, the estimated ages ranged from 1 to 5 years old, similarly to the findings of Cakir et al. (2005) and Bayhan et al. (2009). Vassilopoulou and Papaconstantinou (1994) determined ages ranging from 0 to 5 years for males (TL range: $70-210 \mathrm{~mm}$ ) and from 0 to 7 years for females (TL range: $65-235 \mathrm{~mm}$ ) in the northern Aegean Sea (the smaller sizes/younger ages could be the result of sampling with an experimental trawl with a cod-end mesh size of $14 \mathrm{~mm}$, smaller than the commercially used size of $40 \mathrm{~mm}$ used in the present study). The observed differences in age composition could be caused by the different distribution of stages/age groups (Grati et al., 2013) or sexes (Gerritsen et al., 2010) across different habitats (depth and substrate type) throughout the life cycle of flatfish.

The spotted flounder population seems to consist of more than three TL length groups during most of the sampling period. Smaller individuals (TL $<130 \mathrm{~mm}$ ) showing a peak at 90-100 $\mathrm{mm}$ may be considered as recruits, indicating that recruitment occurs from late spring to early winter, a fact confirmed also by the presence of recruits during the MEDITS catches in summer 2014 (Lefkaditou, unpublished data).

The sequence of monthly length compositions and the temporal fluctuations of GSI in juveniles (Supplementary Fig. 2) indicated gradual growth and maturation of recruited individuals from November to May. These individuals comprised the bulk of the trawl catches. As shown by the monthly percentages of maturity stages and the evolution of the GSI by capture date (for all fish or taking into account only adult fish), the population's spawning period lasts from midsummer to late autumn. The CF and HSI that indicate the robustness of individuals peaked in late spring to early summer with trends opposite to that of the GSI. However, the HSI showed a small drop between February and April, which was more evident for juveniles, as the fish needed to consume the lipid content stored in their liver toward the beginning of the cold winter period. Carreras-Aubets et al. (2011) estimated a higher hepatosomatic index and condition factor values for the same species in the north-western Mediterranean compared to the present study. The reason why fish in the northwestern Mediterranean are more robust might be explained by the difference in productivity between the two areas (e.g. Papathanasiou and Zenetos, 2005).

In a number of studies, fish biological variables and distribution have been documented to fluctuate with depth (e.g. Damalas et al., 2010; Furey et al., 2013). In the present work, the hepatosomatic index fluctuations indicate higher long-term energy reserves in fish living in shallower depths. However, a relationship between total length and depth (that would confirm the bigger-deeper hypothesis - a tendency for larger individuals with increasing depth) was not documented for the spotted flounder, even though it has been documented for other Pleuronectiformes and even for the sympatric flounder Citharus macrolepidotus in the northwestern Mediterranean (Macpherson and Duarte, 1991). Similarly, the models did not indicate significant effects of depth on the CPUE of each gear separately. However, the seasonal fluctuations of CPUEs of the different gears point toward seasonal depth distribution patterns: the peaks of CPUE in gillnets and trammel nets on days 280 and 330 seemed to be another indication of 

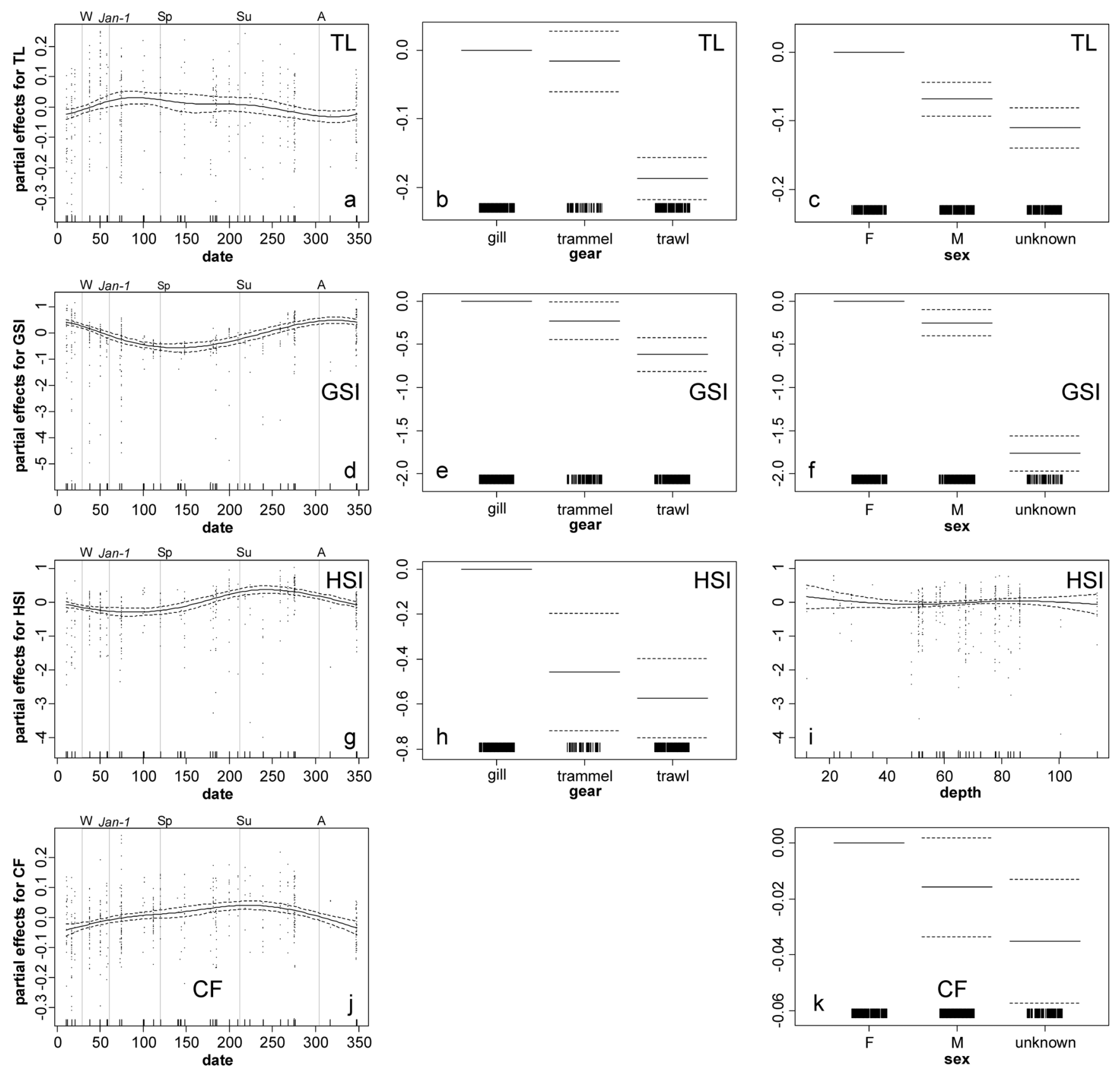

Fig. 5. Effect of statistically significant independent variables on the dependent variables examined according to the generalized additive models (GAMs) results. Dashed lines indicate $95 \%$ confidence intervals. Top row: total length (TL), second row: gonadosomatic index (GSI), third row: hepatosomatic index (HSI), bottom: condition factor (CF). Day number=0: 31/10/2013 (first sampling day for catch data). Unknown: unidentified sex (immature individuals of stage- 1 or individuals at spent gonad stage unidentifiable regarding sex). First day of each season and January 1 st indicated by vertical lines.

recruitment of the young age class at the end of summer/early autumn in shallow water. The high CPUEs of trammel nets compared to gillnets at the beginning of the sampling period could be an indication that, in November, the fish were distributed in shallow waters (and indeed, even for trammel nets the highest abundances were found between 20 and $30 \mathrm{~m}$ ). Regarding trawls for which the sampling scheme corresponded to a wider area, only the probability to catch fish was found to be significantly affected by the explanatory variables longitude and date, indicating highest values in the Patraikos Gulf (highest longitudes) and perhaps a year with higher abundances (2014) following the initial sampling year of the study (2013). Even though no significant effects were found for any of the tested explanatory variables for both presence-absence and abundance models for any single gear, the effects of presence-absence models would indicate the 
Table 2. Results of the generalized additive models (GAMs) on the effects of depth, day of fishing, longitude and latitude (independent variables) on spotted flounder CPUE for the gears trawl, trammel net and gillnet. In trawl and trammel net the Delta-X-error method was employed; hence a different model was constructed for the presence-absence (PA) data and for the positive/non-zero abundance (NZA) data. All variables are denoted by $\mathrm{s}()$ as they were considered continuous and a spline was used for fitting. Chi-square values (presence-absence tests) or $F$-values of the analysis of deviance (NZA/abundance tests) are indicated for each independent (explanatory) variable. Variables denoted by "-" were not included according to the Akaike information criterion selection. Significant effects at the 0.05 confidence level are denoted by an asterisk and in bold typeface. The percentage of deviance explained by the final model (including only the variables with significant effects) is also indicated.

\begin{tabular}{|c|c|c|c|c|c|c|}
\hline Sample & Dependent variable & \multicolumn{4}{|c|}{ Independent variables } & Deviance explained (\%) \\
\hline Trawl & PA & $5.05^{*}$ & - & $5.87^{*}$ & - & 16.30 \\
\hline Trammel net & PA & 3.87 & 0.02 & - & 2.65 & 9.20 \\
\hline Gillnet & Abundance & 3.03* & - & 0.36 & - & 37.50 \\
\hline
\end{tabular}
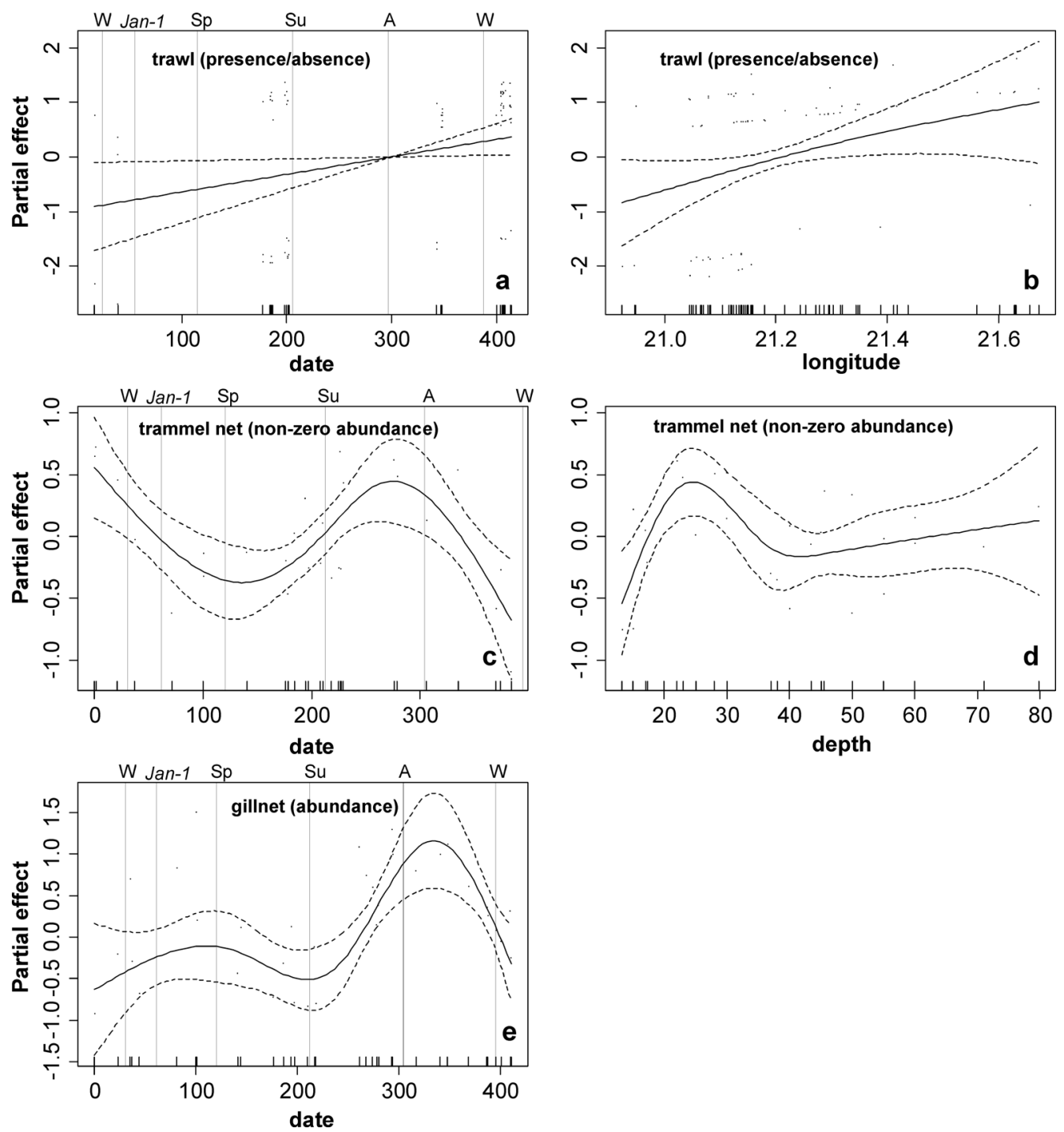

Fig. 6. Effect of statistically significant independent variables on CPUE according to the generalized additive models (GAMs) results. Dashed lines indicate $95 \%$ confidence intervals. Top: trawl presence/absence data, middle: trammel net non-zero (positive values) abundance data, bottom: gillnet abundance data. Day number $=0: 31 / 10 / 2013$ (first sampling day). First day of each season and January 1st indicated by vertical lines. 

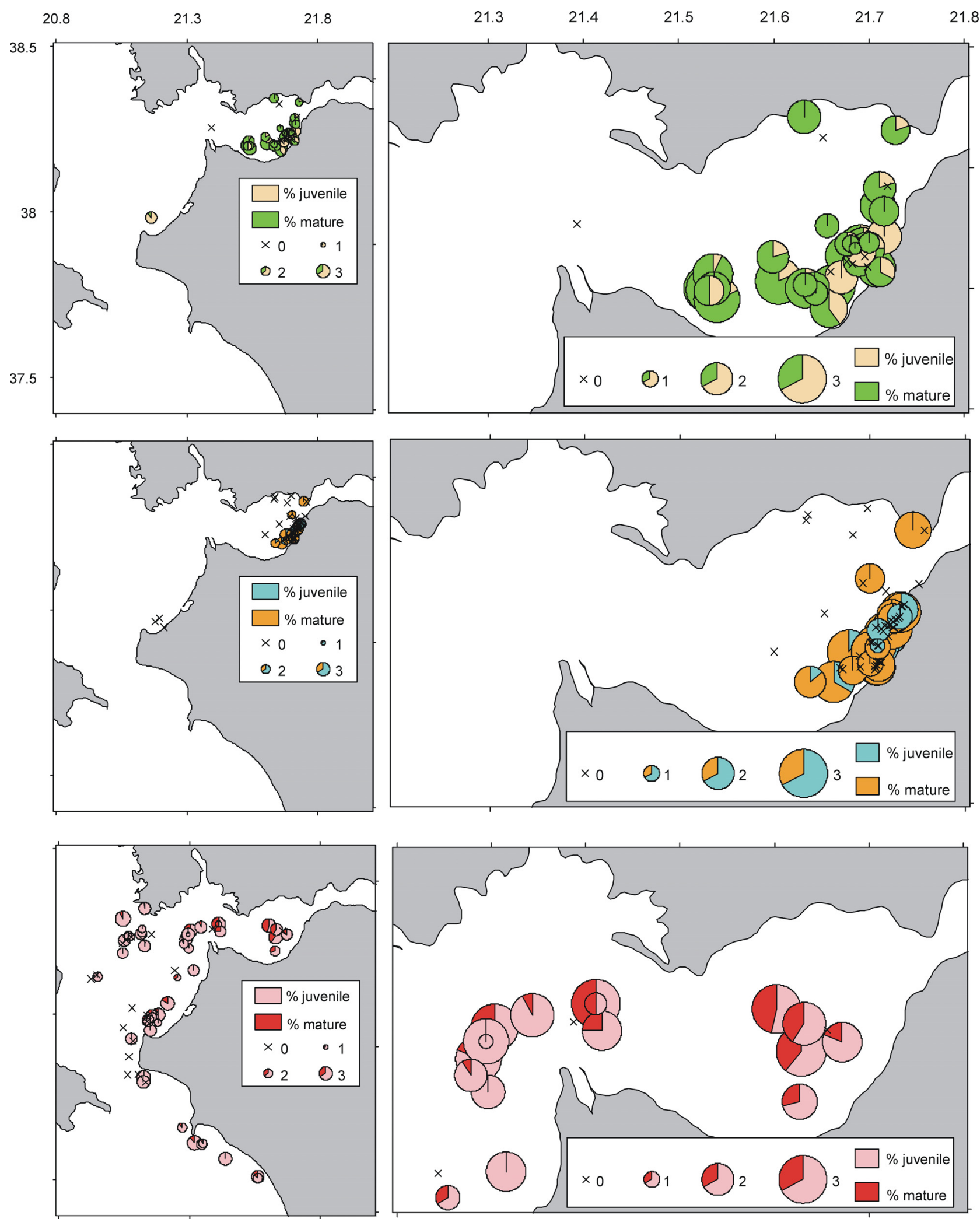

Fig. 7. Distribution of log-transformed CPUE (in kg/gear unit of effort) for each fishing gear (top: gillnet, middle: trammel net, bottom: trawl) with a focus in the Patraikos Gulf for each gear (right). The relevant composition in juvenile and adults (potentially mature) spotted flounder based on total length measurements and the length at maturity estimated is presented. 


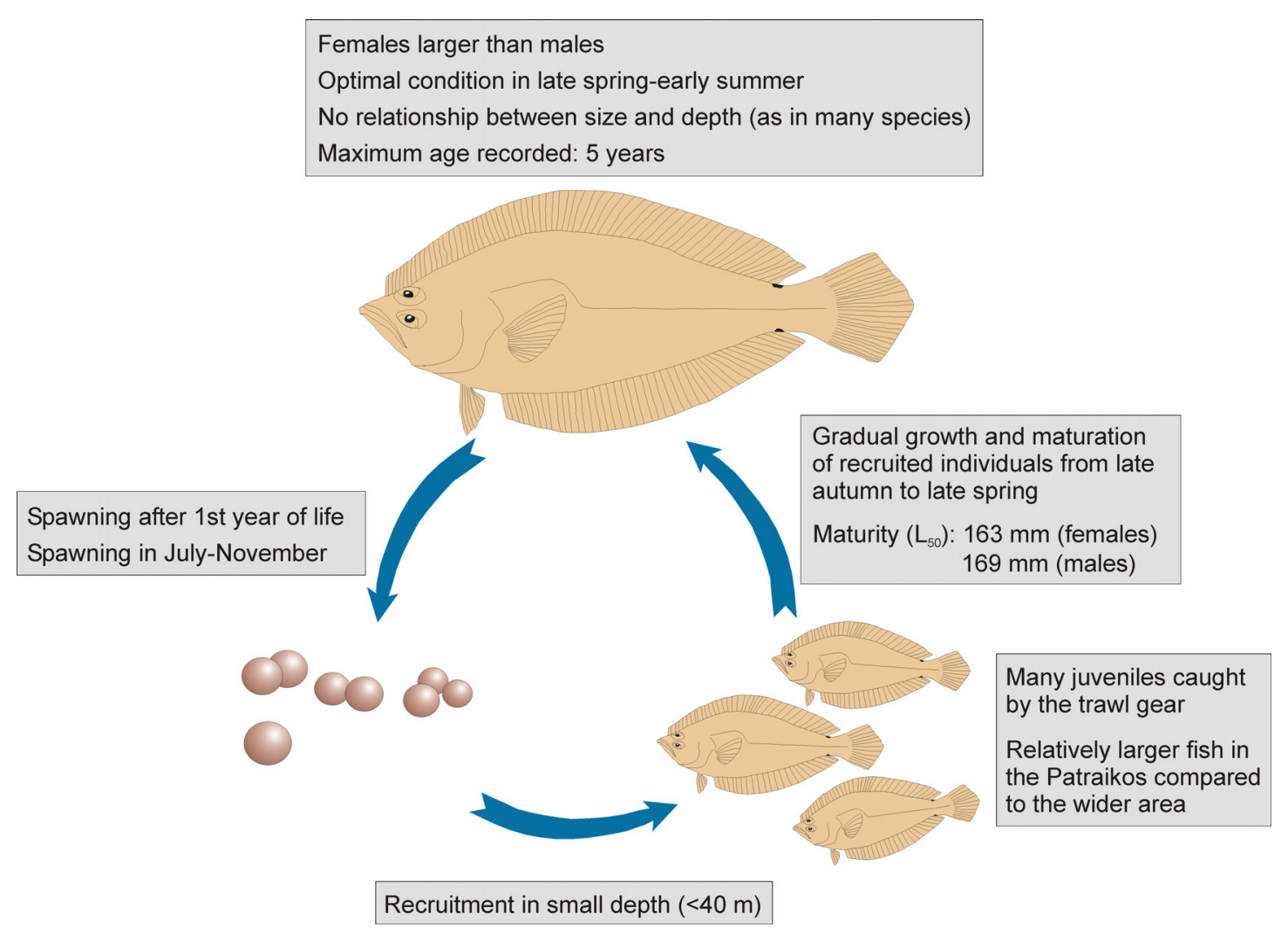

Fig. 8. Overview of the life cycle of the spotted flounder in the Patraikos Gulf and the adjacent central Ionian Sea.

spatiotemporal coordinates where a gear is expected to catch fish, while the effects of positive abundance models would show where and when this gear is expected to catch high abundances. These elements are related not only to fish abundance, but also to the distribution pattern of the population in space and time.

Together with the common sole (Solea vulgaris) and the four-spot megrim (Lepidorhombus boscii), the spotted flounder is one of the most important flatfish species for fisheries in the Mediterranean Sea (Sartor et al., 2002). There is not, however, an established minimum landing size for this species in the Mediterranean. While the spotted flounder is not a commercially targeted species in Greece and, despite being marketed, parts of its catches are frequently discarded, the findings of the present study could be used to improve fisheries management. The management of fish stocks in the study area is particularly challenging due to the multi-gear character of Mediterranean fisheries and the overlap in fish caught by different gears. The lower length, GSI and HSI values found in fish individuals caught by trawl fisheries indicate that the catching of immature individuals by trawls should be managed. de Juan et al. (2007) documented that the spotted flounder has a low resilience to trawling activity in the northwestern Mediterranean. The overlap between the period of the Greek nation-wide trawl ban (from June to October) and particularly that for the inner part of Patraikos Gulf (April to November) with the recruitment season (late spring to early winter) is arguably favorable for the spotted flounder population in the area. A similar ban of trawling in recruitment areas in this critical period has been suggested for the common sole (Scarcella et al., 2014).
The finding that juveniles (TL $<166 \mathrm{~mm}$ ) dominated trawl catches in winter and spring (Supplementary Fig. 1b) in the wider central Ionian Sea, indicates that additional fishery regulations might be necessary to improve bottom trawl gear selectivity. A study on bottom trawl selectivity carried out in the western Aegean Sea showed that a diamond stretched codend mesh size of $40 \mathrm{~mm}$ (as applied after Council Regulation No. 1626/1994) retains a remarkably lower proportion of spotted flounder individuals $(29 \%)$, than the diamond stretched mesh size of $28 \mathrm{~mm}(99 \%)$ previously used by Greek trawlers. It was also more effective than the tested square stretched mesh size of $40 \mathrm{~mm}$ which retained $53 \%$ (Stergiou, 1999). Ordines et al. (2006) estimated a $\mathrm{TL}_{50}$ of $\sim 12 \mathrm{~cm}$ for a cod-end mesh size of $40 \mathrm{~mm}$, without noting differences between meshes of diamond and square shape.

Fisheries biology studies usually focus on target species and not on species of low commercial value like the spotted flounder, despite its high abundance in the continental shelf (e.g. Lucchetti, 2008). Apart from the interest in the populations examined, it is natural that sampling a bycatch population can be arduous. Furthermore, the fact that fishing vessels do not target this population may make the results uncertain (e.g. the unclear patterns regarding geographic coordinates as explanatory variables of spotted flounder CPUE in the present study). Further studies on species of low commercial value may contribute to a better understanding of the impacts of fisheries on demersal stocks and the benthic ecosystem as a whole. The methodology adopted in this work, combining typical fisheries biology for the estimation of reference points and modeling to determine spatio-temporal patterns, seems to be a promising approach toward that end. 


\section{Supplementary Material}

Supplementary Fig. 1. (a) Length frequencies of individuals measured on-board commercial fishing vessels in the study area by gear (all months). (b) Length frequencies of individuals measured on-board commercial fishing vessels in the study area by gear and month.

Supplementary Fig. 2. (a) Effect of statistically significant independent variables on the dependent variables examined according to the generalized additive models (GAMs) results for juvenile fish $\left(\mathrm{TL}<\mathrm{TL}_{50}\right)$. Dashed lines indicate $95 \%$ confidence intervals. Top row: total length (TL), second row: gonadosomatic index (GSI), third row: hepatosomatic index (HSI), bottom: condition factor (CF). Day number $=0: 31 / 10 / 2013$ (first sampling day for catch data). Unknown: unidentified sex (immature individuals of stage-1 or individuals at spent gonad stage unidentifiable regarding sex). Partial effect of depth on HSI is denoted by light grey to indicate it is not comparable with the other graphs in the same panel column. (b) Effect of statistically significant independent variables on the dependent variables examined according to the generalized additive models (GAMs) results for adult (potentially mature) fish. Dashed lines indicate $95 \%$ confidence intervals. Top row: total length (TL), second row: gonadosomatic index (GSI), third row: hepatosomatic index (HSI), bottom: condition factor (CF). Day number $=0$ : 31/10/2013 (first sampling day for catch data). Unknown: unidentified sex (immature individuals of stage-1 or individuals at spent gonad stage unidentifiable regarding sex). Supplementary Table 1. Variable selection for inclusion in generalized additive models based on Akaike information criterion (AIC). Selected combinations of variables for inclusion in each final model (based on lowest AIC) are denoted in grey. $\Delta$-AIC: difference between each model's AIC and the AIC of the model finally selected. (A) Models on total length (TL), gonadosomatic index, (GSI), hepatosomatic index (HSI), condition factor (CF)-individual fish data. (B) Models on CPUE-catch data: Delta-X-error model for trawl and trammel net (separate modeling of presence-absence and positive/non-zero abundance values) and abundance for gillnet. lon: longitude, lat: latitude.

Supplementary Table 2. Age-length key for males, females and total fish (including immature fish). U: Age not discerned.

The Supplementary Material is available at http://www.alrjournal.org/10.1051/alr/2017032/olm.

Acknowledgements. The authors would like to thank the editor-in-chief, the associate editor and two anonymous referees for their constructive comments that helped us significantly improve the manuscript. We would also like to thank Katharina Urbantat for English language editing.

\section{References}

Anonymous. International bottom trawl survey in the Mediterranean, Instruction manual, Version 7, MEDITS Working Group, 2013, $120 \mathrm{p}$.

Armsworthy SL, Campana SE. 2010. Age determination, bombradiocarbon validation and growth of Atlantic halibut (Hippoglossus hippoglossus) from the Northwest Atlantic. Environ Biol Fish 89: 279-295.
Bayhan B, Sever TM, Taskavak E. 2009. Age and feeding habits of Atlantic spotted flounder Citharus linguatula (Linnaeus, 1758) (Pisces: Pleuronectiformes) from central Aegean Sea of Turkey. North-West J Zool 5: 330-337.

Bettoso N, Borme D, Faresi L, Aleffi I, Orlando-Bonaca M, Lipej L. 2016. New insights on the biological parameters of the exploited cuttlefish Sepia officinalis L. (Mollusca: Cephalopoda) in the northern Adriatic Sea in relation to the main fishing gears employed. Mediterr Mar Sci 17: 152-162.

Cabral HN, Vasconcelos R, Vinagre C, França S, Fonseca V, Maia A, Reis-Santos P, Lopes M, Ruano M, Campos J, Freitas V, Santos PT, Costa MJ. 2007. Relative importance of estuarine flatfish nurseries along the Portuguese coast. J Sea Res 57: 209-217.

Caddy J. 1997. Checks and balances in the management of marine fish stocks: Organizational requirements for a limit reference point approach. Fish Res 30: 1-15.

Cakir T, Bayhan B, Hossucu B. 2005. Some parameters of the population biology of spotted flounder (Citharus linguatula Linnaeus, 1758) in Edremit Bay (North Aegean Sea). Turk J Vet Anim Sci 29: 1013-1018.

Carbonara P, Intini S, Modugno E, Maradonna F, Spedicato MT, Lembo G. Zupa W, Carnevali O. 2015. Reproductive biology characteristics of red mullet (Mullus barbatus L., 1758) in Southern Adriatic Sea and management implications. Aquat Living Resour 28: 21-31.

Carpentieri P, Cantarelli T, Colloca F, Criscoli A, Ardizzone G. 2010. Feeding behaviour and daily ration of the spotted flounder Citharus linguatula (Osteichthyes: Pleuronectiformes) in the central Tyrrhenian Sea. Sci Mar 74: 659-667.

Carreras-Aubets M, Montero FE, Padros F, Crespo S, Carrasson M. 2011. Parasites and histopathology of Mullus barbatus and Citharus linguatula (Pisces) from two sites in the NW Mediterranean with different degrees of pollution. Sci Mar 75: 369-378.

Cengiz Ö, Özekinci U, İsmen A, Öztekin A. 2013. Age and growth of the four-spotted megrim (Lepidorhombus boscii Risso, 1810) from Saros Bay (Northern Aegean Sea, Turkey). Mediterr Mar Sci 14: $36-44$.

Cengiz Ö, Ismen A, Ozekinci U. 2014. Reproductive biology of the spotted flounder, Citharus linguatula (Actinopterygii: Pleuronectiformes: Citharidae), from Saros Bay (northern Aegean Sea, Turkey). Acta Ichthyol Piscat 44: 123-129.

Chambers JM, Hastie TJ. Statistical models, in: J.M. Chambers, T.J. Hastie (Eds.), Statistical models in S, Chapman and Hall, London, 1992, pp. 13-44.

Damalas D, Maravelias CD, Katsanevakis S, Karageorgis AP, Papaconstantinou C. 2010. Seasonal abundance of non-commercial demersal fish in the eastern Mediterranean Sea in relation to hydrographic and sediment characteristics. Estuar Coast Shelf Sci 89: 107-118.

de Juan S, Thrush S, Demestre M. 2007. Functional changes as indicator of trawling disturbance on a benthic community from a fishing ground (NW Mediterranean). Mar Ecol Prog Ser 334: 117-129.

Dimitriadis C, Borthagaray AI, Vilela R, Casadevall M, Carranza A. 2016. A network approach to by-catch in a multi-species Mediterranean small-scale fishery. Fish Res 173: 273-281.

Erzini K, Gonçalves JMS, Bentes L, Lino PG, Ribeiro J, Stergiou KI. 2003. Quantifying the roles of competing static gears: comparative selectivity of longlines and monofilament gill nets in a multispecies fishery of the Algarve (southern Portugal). Sci Mar 67: 341-352.

Fabio P, Silvia C, Paolo V, Anelli Monti M. 2016. Present and future status of artisanal fisheries in the Adriatic Sea (western Mediterranean Sea). Ocean Coast Manag 122: 49-56. 
Florin A-B, Sundblad G, Bergström U. 2009. Characterisation of juvenile flatfish habitats in the Baltic Sea. Estuar Coast Shelf Sci 82: 294-300.

Fryer RJ. 1991. A model of between-haul variation in selectivity. ICES J Mar Sci 48: 281-290.

Furey NB, Rooker JR. 2013. Spatial and temporal shifts in suitable habitat of juvenile southern flounder (Paralichthys lethostigma). $J$ Sea Res 76: 161-169.

Furey NB, Dance MA, Rooker JR. 2013. Fine-scale movements and habitat use of juvenile southern flounder Paralichthys lethostigma in an estuarine seascape. J Fish Biol 82: 1469-1483.

Garcia SM, Cochrane KL. 2005. Ecosystem approach to fisheries: a review of implementation guidelines. ICES J Mar Sci 62: 311-318.

Garcia-Rodríguez M, Esteban A. Contribution to the knowledge of Citharus linguatula (Linnaeus, 1758) (Osteicthyes: Heterosomata) in the Iberian Mediterranean, in: IFREMER: Actes de colloques No. 26, 2000, pp. 131-140.

Gerritsen HD, McGrath D, Lordan C, Harlay X. 2010. Differences in habitat selection of male and female megrim (Lepidorhombus whiffiagonis, Walbaum) to the west of Ireland. A result of differences in life-history strategies between the sexes? J Sea Res 64: 487-493.

Gibson RN. 1994. Impact of habitat quality and quantity on the recruitment of juvenile flatfishes. Neth J Sea Res 32: 191-206.

Gordo LS, Neves A, Vieira AR, Paiva RB, Sequeira V. 2016. Age, growth and mortality of the comber Serranus cabrilla (Linnaeus, 1758) in the Eastern Atlantic. Mar Biol Res 12: 656-662.

Grati F, Scarcella G, Polidori P, Domenichetti F, Bolognini L, Gramolini R, Vasapollo C, Giovanardi O, Raicevich S, Celić I, Vrgoč N, Isajlovic I, Jenič A, Marčeta B, Fabi G. 2013. Multiannual investigation of the spatial distributions of juvenile and adult sole (Solea solea L.) in the Adriatic Sea (northern Mediterranean). J Sea Res 84: 122-132.

Gurbet R, Akyol O, Yalçin E, Özaydin O. 2013. Discards in bottom trawl fishery in the Aegean Sea (Izmir Bay, Turkey). $J$ Appl Ichthyol 29: 1269-1274.

Hastie TJ, Tibshirani RJ. Generalized additive models, Chapman and Hall, London, 1990, 352 p.

Haynes PS, Brophy D, McGrath D. 2014. The timing of early life events and growth rate estimates of age- 0 year group brill Scophthalmus rhombus along the west coast of Ireland. J Fish Biol 84: 225-230.

Jin S, Yan X, Zhang H, Fan W. 2015. Weight-length relationships and Fulton's condition factors of skipjack tuna (Katsuwonus pelamis) in the western and central Pacific Ocean. PeerJ 3: e758, doi: 10.7717 peerj. 758 .

Keller S, Quetglas A, Puerta P, Bitetto I, Casciaro L, Cuccu D, Esteban A, Garcia C, Garofalo G, Guijarro B, Josephides M, Jadaud A, Lefkaditou E, Maiorano P, Manfredi C, Marceta B, Micallef R, Peristeraki P, Relini G, Sartor P, Spedicato MT, Tserpes G, Hidalgo M. 2017. Environmentally driven synchronies of Mediterranean cephalopod populations. Prog Oceanogr 152: $1-14$.

Koutsidi M, Tzanatos E, Machias A, Vassilopoulou V. 2016. Fishing for function: the use of biological traits to evaluate the effects of multi-species fisheries on the functioning of fisheries assemblages. ICES J Mar Sci 73: 1091-1103.

Landa J, Piñeiro C. 2000. Megrim (Lepidorhombus whiffiagonis) growth in the North-eastern Atlantic based on back-calculation of otolith rings. ICES J Mar Sci 57: 1077-1090.

Lee H-H, Piner KR, Hinton MG, Chang Y-J, Kimoto A, Kanaiwa M, Su N-J, Walsh W, Sun C-L, Di Nardo G. 2014. Sex-structured population dynamics of blue marlin Makaira nigricans in the Pacific Ocean. Fish Sci 80: 869-878.
Lleonart J, Maynou F, Recasens L, Franquesa R. 2003. A bioeconomic model for Mediterranean fisheries, the hake off Catalonia (western Mediterranean) as a case study. Sci Mar 67 (Suppl. 1): 337-351.

Lozán JL. 1992. Sexual differences in food intake, digestive tract size and growth performance of the dab, Limanda limanda. Neth J Sea Res 29: 223-227.

Lucchetti A. 2008. Comparison of diamond-and square-mesh codends in the hake (Merluccius merluccius L. 1758) trawl fishery of the Adriatic Sea (central Mediterranean). Sci Mar 72: 451-460.

Machias A, Vassilopoulou V, Vatsos D, Bekas P, Kallianiotis A, Papaconstantinou C, Tsimenides N. 2001. Bottom trawl discards in the northeastern Mediterranean Sea. Fish Res 53: 181-195.

Macpherson E, Duarte CM. 1991. Bathymetric trends in demersal fish size: is there a general relationship? Mar Ecol Prog Ser 71: 103-112.

Martin P, Sartor P, Garcia-Rodriguez M. 1999. Exploitation patterns of the European hake Merluccius merluccius, red mullet Mullus barbatus and striped red mullet Mullus surmuletus in the western Mediterranean. J Appl Ichthyol 15: 24-28.

Matić-Skoko S, Ferri J, Tutman P, Skaramuca D, Dikic D, Lisicic D, Franić Z, Skaramuca B. 2012. The age, growth and feeding habits of the European conger eel, Conger conger (L.) in the Adriatic Sea. Mar Biol Res 8: 1012-1018.

Nielsen JG. Citharidae, in: P.J.P. Whitehead, M.-L. Bauchot, J.-C. Hureau, J. Nielsen, E. Tortonese (Eds.), Fishes of the Northeastern Atlantic and the Mediterranean, Vol. III, UNESCO, Paris, 1986, p. 1286.

Ordines F, Massutí E, Guijarro B, Mas R. 2006. Diamond vs. square mesh codend in a multi-species trawl fishery of the western Mediterranean: effects on catch composition, yield, size selectivity and discards. Aquat Living Resour 19: 329-338.

Papathanasiou E, Zenetos A. State of the Hellenic marine environment, Hellenic Centre for Marine Research, Insitute of Oceanography, Athens, 2005, 360 p.

Planas A, Vives F. 1956. Contribucion al estudio de la solleta (Citharus linguatula Gunth) del Mediterraneo occidental. Invest Pesq 3: 107-131.

$\mathrm{R}$ Development Core Team. R: a language and environment for statistical computing, R Foundation for Statistical Computing, Vienna, Austria, 2008, ISBN 3-900051-07-0, http://www.Rproject.org.

Sandman A, Isaeus M, Bergstrom U, Kautsky H. 2008. Spatial predictions of Baltic phytobenthic communities: measuring robustness of generalized additive models based on transect data. J Mar Syst 74: 586-596.

Sartor P, Sbrana M, Ungaro N, Marano C, Piccinetti C, Manfrin G. 2002. Distribution and abundance of Citharus linguatula, Lepidorhombus boscii, and Solea vulgaris (Osteichthyes: Pleuronectiformes) in the Mediterannean sea. Sci Mar 66: 83-102.

Scarcella G, Grati F, Raicevich S, Russo T, Gramolini R, Scott RD, Polidori P, Domenichetti F, Bolognini L, Giovanardi O, Celić I, Sabatini L, Vrgoč N, Isajlović I, Marčeta B, Fabi G. 2014. Common sole in the northern and central Adriatic Sea: spatial management scenarios to rebuild the stock. J Sea Res 89: 12-22.

Stergiou KI. 1999. Effects of changes in the size and shape of codend on catch of Aegean Sea fishes. ICES J Mar Sci 56: 96-102.

Stergiou KI, Erzini K. 2002. Comparative fixed gear studies in the Cyclades (Aegean Sea): size selectivity of small-hook longlines and monofilament gill nets. Fish Res 58: 25-40.

Teixeira CM, Batista I, Cabral HN. 2010. Diet, growth and reproduction of four flatfishes on the Portuguese coast. Sci Mar 74: 223-233. 
Tserpes G, Tzanatos E, Peristeraki P. 2011. Spatial management of the Mediterranean bottom-trawl fisheries: the case of the southern Aegean Sea. Hydrobiologia 670: 267-274.

Tzanatos E, Somarakis S, Tserpes G, Koutsikopoulos C. 2007. Discarding practices in a Mediterranean small-scale fishing fleet (Patraikos Gulf, Greece). Fish Manag Ecol 14: 277-285.

Van der Veer HW, Berghahn R, Miller JM, Rijnsdorp AD. 2000. Recruitment in flatfish, with special emphasis on North Atlantic species: progress made by the Flatfish Symposia. ICES J Mar Sci 57: 202-215.

Vassilopoulou V, Papaconstantinou C. 1994. Age, growth and mortality of the spotted flounder (Citharus linguatula Linnaeus, 1758) in the Aegean Sea. Sci Mar 58: 261-267.

Vignaux M. 1996. Analysis of spatial structure in fish distribution using commercial catch and effort data from the New Zealand hoki fishery. Can J Fish Aquat Sci 53: 963-973.

Wilson MT, Mier KL, Cooper DW. 2016. Assessment of resource selection models to predict occurrence of five juvenile flatfish species (Pleuronectidae) over the continental shelf in the western Gulf of Alaska. J Sea Res 111: 54-64.
Winker H, Kerwath SE, Attwood CG. 2013. Comparison of two approaches to standardize catch-per-unit-effort for targeting behaviour in a multispecies hand-line fishery. Fish Res 139: 118-131.

Wood SN. Generalized additive models: an introduction with R, Chapman and Hall/CRC, London, 2006, 392 p.

Wootton RJ. Ecology of teleost fishes, Kluwer Academic Publishers, Dordrecht, 1998, 386 p.

Yamashita Y, Otake T, Yamada H. 2000. Relative contributions from exposed inshore and estuarine nursery grounds to the recruitment of stone flounder, Platichthys bicoloratus, estimated using otolith Sr:Ca ratios. Fish Oceanogr 9: 316-327.

Yeung C, Yang M-S. 2017. Habitat quality of the coastal southeastern Bering Sea for juvenile flatfishes from the relationships between diet, body condition and prey availability. J Sea Res 119: 17-27.

Zucchetta M, Franco A, Torricelli P, Franzoi P. 2010. Habitat distribution model for European flounder juveniles in the Venice lagoon. J Sea Res 64: 133-144.

Cite this article as: Pappa M, Chychykalo A, Koutsidi M, Mavraki N, Lefkaditou E, Koutsikopoulos C, Tzanatos E. 2017. Biology and fisheries of the spotted flounder (Citharus linguatula) caught by multiple gears with partial spatiotemporal overlaps. Aquat. Living Resour. 30: 32 